\title{
Upaya Penetrasi dengan Enumeration menggunakan Hydra
}

\author{
Andre Arta Kurniawan ${ }^{1}$ Yahya Nugroho $^{2}$ \\ Program Studi/Jurusan Teknik Komputer, Institut Bisnis dan Informatika Stikom Surabaya, \\ Email: ${ }^{1}$ andrearta1@gmail.com, ${ }^{2}$ yahya.nvf31@gmail.com
}

\begin{abstract}
Abstrak: Internet di jaman sekarang sudah dapat dikatakan sebagai menjadi suatu kebutuhan untuk beberapa orang yang bergerak dalam teknologi internet. Namun di sisi lain ancaman terhadap internet juga akan semakin terus bertambah. Salah satu kejahatan yang ada pada internet adalah cyber-crime atau kejahatan internet dan kejahatan internet juga dapat dilakukan oleh siapa saja salah satunya hacker. Apabila seorang hacker berhasil meretas sebuah jaringan atau server maka tak diragukan lagi hacker tersebut dapat mengakses seluruh jaringan dan menggunakan setiap data yang ada, maka dari itu diperlukan seorang network administrator yang handal dalam menangani sebuah jaringan atau sebuah server. Pada jurnal ini mengamati langkah yang dilakukan oleh Attacker mendapatkan akses ke user menggunakan tools hydra, lama cracking password user membutuhkan rata-rata waktu sekitar 4 jam.
\end{abstract}

Kata Kunci: cyber-crime, hacker, cracking password,enumeration, hydra

\begin{abstract}
Today's internet can be said to be a necessity for some people who are engaged in internet technology. But on the other hand the threat to the internet will also continue to grow. One of the crimes that are on the internet is cyber-crime or internet-crime and internet-crime can also be done by anyone, one of them is a hacker. If a hacker succeeds in hacking a network or server then the hacker is undoubtedly able to access the entire network and use every available data, therefore a reliable network administrator is required to handle a network or a server. In this journal observing the steps taken by the Attacker gain access to the user using the hydra tools. In this journal observing the steps taken by the Attacker to gain access to the user using the Hydra tools, the length of cracking the user password requires an average of about 4 hours.
\end{abstract}

Keywords: cyber-crime, hacker, cracking password,enumeration, hydra

\section{PENDAHULUAN}

Di era teknologi internet yang sudah sangat maju ini memang sangat penting dibutuhkannya sebuah keamanan dalam sebuah jaringan, karena mengingat seiring majunya teknologi internet jumlah cyber-crime juga akan terus meningkat. Sebuah jaringan akan memerlukan network administrator yang handal dalam menangani sebuah jaringan, terutama dalam urusan keamanan jaringan. Network administrator harus bisa mengatasi apabila suatu waktu jaringan yang dikontrolnya mengalami serangan hacker. Tujuan dari keamanan komputer sendiri adalah melindungi informasi komputer yang berada di dalamnya. [1]
Sebuah jaringan tanpa kemanan pun juga sangat berbahaya apabila jaringan tersebut setiap harinya diakses dan digunakan. Terlebih para hacker akan dengan mudah masuk kedalam jaringan dan menyerang sebuah server. Dengan tidak adanya keamannya pada sistem maka akan banyak para Hacker yang dengan mudah dapat mengambil alih sistem yang dibangun. [2] Ada berbagai jenis macam serangan yang dapat dilakukan oleh para hacker yang dapat digunakan untuk menyerang sebuah server, salah satunya dengan penetration. Dengan melakukan penetration, hacker akan berusaha masuk melalui celah keamanan yang terbuka dari server tersebut. Dan apabila hacker berhasil masuk ke 
dalam server dan mendapatkan akses penuh terhadap server maka bukan tidak mungkin lagi hacker dapat dengan mudah dapat mengakses setiap data yang terdapat di dalam server tersebut. Kebocoran data dan informasi merupakan hal yang fatal. Data-data tersebut dapat disalahgunakan oleh pihak yang tidak bertanggung jawab. [3]

Namun, bagi sebagian orang bekerja untuk sebuah jaringan atau network administrator, mereka akan melakukan sendiri penetration ke dalam jaringan mereka sendiri sehingga kegiatan tersebut disebut dengan penetration testing.

Pada jurnal ini, upaya penetrasi dilakukan dengan cara menyelundup ke user akses terlebih dahulu, dengan cara enumeration. Enumeration merupakan salah satu usaha dari attacker untuk mendapatkan hak ases dengan mencoba berbagai kemungkinan password dari generator hash. Enumeration dapat dilakukan dengan menggunakan beberapa tolos yang opensource seperti hydra, medusa, dan John The Ripper. Jurnal ini menerapkan tools hydra untuk men-cracking password.

\section{METODOLOGI PENETRATION Teknik Penetration}

Dalam melakukan penetration seorang network administrator harus melakukan beberapa tahapan untuk kemudian menganalisa apakah server tersebut masih memiliki celah keamanan atau tidak. Jika masih ditemukan celah kemanan maka server tersebut masih diperlukan solusi untuk memperbaiki celah kemanan. Keamanan jaringan ini dapat bertujuan untuk agar pemilik sistem informasi dapat menjaga sistem informasinya tidak ditembus atau disusupi oleh orang lain yang pada akhirnya dapat merusak sistem. [4] Untuk menerapkan teknologi yang aman perlu adanya perancangan sebuah sistem keamanan jaringan yang bagus. [5]

Tujuan lain dalam melakukan penetration adalah menentukan dan mengetahui kemungkinan - kemungkinan yang dapat terjadi apabila seorang hacker melakukan serangan terhadap server, serta dampak yang dihasilkan dari hasil eksploitasi server yang dilakukan oleh hacker.

Adapun tahapan yang harus dilakukan untuk melakukan penetration adalah sebagai berikut :
1. Footprinting = umunya digunakan untuk mengumpulkan informasi sebanyak mungkin mengenai target yang akan diserang baik itu server maupun jaringan yang akan diserang. Dengan melakukan footprinting, attacker akan berusaha untuk mendapatkan informasi sebanyak mungkin mengenai target yang akan diserang, mulai dari IP Addresses, name server, hingga informasi mengenai server.

2. Scanning = dengan melakukan scanning, attacker akan mengumpulkan port list yang terbuka. Dari port list yang terbuka, attacker akan mengetahui dari mana attacker bisa menyerang

3. Enumeration $=$ dengan melakukan enumeration, attacker akan mencari user account yang aktif atau valid dari target. Dengan memanfaatkan user ini attacker akan mencoba masuk kedalam server.

Enumeration merupakan salah satu cara oleh attacker untuk mendapatkan informasi mengenai username, nama mesin, dan resource jaringan.

Salah satu tools yang bisa digunakan untuk melakukan enumeration ini adalah dengan menggunakan medusa, hydra, john the ripper, dan lain-lain. Pada jurnal ini, penerapannya menggunakan tools hydra pada linux.

- Hydra merupakan salah tools yang disedikan oleh Kali Linux, untuk mencracking password sesuai dengan wordlist user dan password. Beberapa contoh 10.000 wordlist dari password disajikan pada tabel berikut,

Tabel 1 Wordlist dari Generate Pasword

\begin{tabular}{|c|c|}
\hline No & Password \\
\hline 1 & A1! ㅇ 1 \\
\hline 2 & $A \div A A 1$ \\
\hline 3 & $\mathrm{~A} \div \mathrm{A} z \mathrm{~A}$ \\
\hline 4 & $A A \div 1 z @$ \\
\hline
\end{tabular}

Tabel 2 Wordlist dari User

\begin{tabular}{lll}
\hline No & User.lst & Nama user \\
\hline 1 & User 1 & felix \\
2 & User 2 & bukcy \\
3 & User 3 & james \\
\hline
\end{tabular}

Sintak yang digunakan pada hydra sebagai berikut : 
hydra -L /root/JoTi/user.lst -P/root/JoTi/password. lst

10.10 .10 .2 -t $4 \mathrm{ssh}-->>$

SSH-server

hydra -L /root/JoTi/user.lst

-P/root/JoTi/password. lst

20.20 .20 .253 -t 4 ssh -->>

user1

hydra -L/root/JoTi/user.lst

-P/root/JoTi/password. lst

20.20 .20 .254 -t 4 ssh -->>

user2

dari sintak tersebut terlihat kemungkinan password yang cocok dari user tersebut. Cepat tidaknya kinerja dari hydra tergantung dari spek resource yang digunakan oleh Attacker dan kompleksitas dari password.

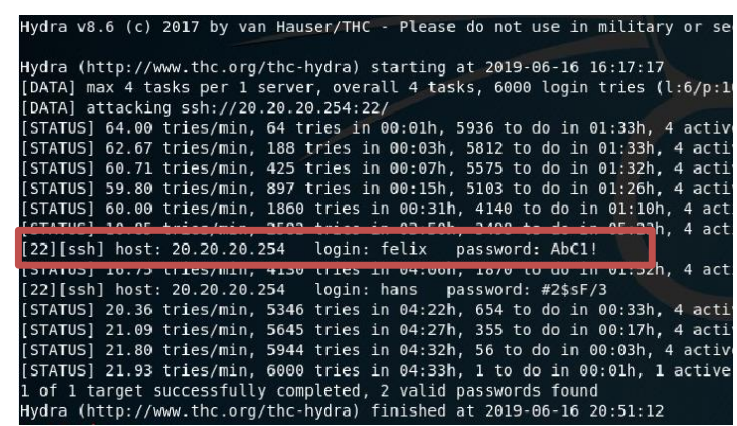

Gambar 1 Enumeration User : felix dengan Hydra

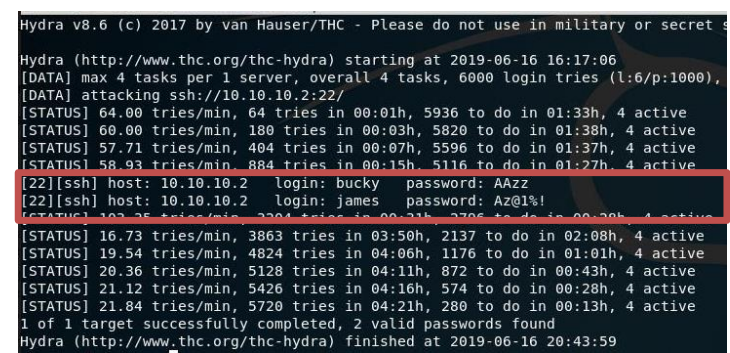

Gambar 2 Enumeration User bucky dan james dengan hydra

4. Gaining Access $=$ Setelah data - data yang diperlukan telah terkumpul, attacker akan mencoba untuk masuk ke dalam server atau mengakses server tersebut

5. Privilege Escalation = Dengan user - user yang ada, attacker akan mencoba masuk ke dalam server. Jika terdapat user yang dapat digunakan masuk ke dalam server, maka selanjutnya attacker akan mencoba untuk mendapatkan full-access terhadap server tersebut.
6. Covering Tracks $=$ Setelah mendapatkan full-access terhadap server maka selanjutnya attacker akan menghapus logs yang ada agar tidak dicurigai.

7. Backdooring $=$ Terakhir, attacker akan mencoba untuk membuat user baru dengan tujuan ketika attacker akan mengakses kembali server tersebut attacker akan masuk dengan user yang telah dibuatnya.

8. Denial of Service = Atau yang lebih sering dikenal dengan DoS attack, serangan ini juga merupakan serangkaian dari penteration attack, dimana ketika seorang attacker gagal menyerang maka attacker akan melakukan Teknik DoS attack.

\section{HASIL DAN PEMBAHASAN}

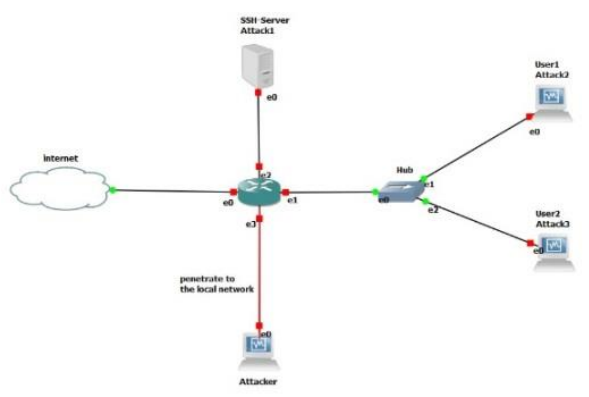

Gambar 3. Topologi yang digunakan untuk penetration

Dari ilustrasi Gambar 3. Rancangan topologi yang digunakan. Pada topologi jaringan, Attacker akan mencoba melakukan penetration dari dalam jaringan langsung atau jaringan lokal. Nantinya attacker akan mencoba untuk cracking password dari user dan SSH-Server yang terdapat pada jaringan tersebut.

Pada hasil percobaan cracking password, password yang digunakan terdiri atas berbagai macam kombinasi password hingga panjang karakter yang digunakan.

Attacker pada percobaan menggunakan sistem operasi Kali Linux v2019.2 dan tools yang digunakan untuk melakukan cracking password adalah menggunakan hydra. 
Tabel 3. Lama Waktu Cracking Password

\begin{tabular}{|c|c|c|c|c|}
\hline & Password & Mulai & Akhir & Lama \\
\hline User 1 & $\begin{array}{l}\text { AAzz } \\
\text { Az@1\%! }\end{array}$ & $16: 17: 06$ & $20: 43: 59$ & $04: 26: 53$ \\
\hline User 2 & $\begin{array}{l}\mathrm{AbC} 1 ! \\
\# 2 \$ s F / 3\end{array}$ & $16: 17: 17$ & $20: 51: 12$ & $04: 33: 55$ \\
\hline User 3 & $\begin{array}{l}\text { AA\%!@A } \\
\text { Aik@1\%!! }\end{array}$ & $16: 17: 13$ & $20: 57: 06$ & 04:39:53 \\
\hline
\end{tabular}

Dari hasil tabel 3. Password yang digunakan adalah hasil generate random passoword dengan menggunakan tools yang ada pada Kali Linux. Password yang digunakan pun juga kombinasi antara panjang karakter yang digunakan dengan jenis karakter yang digunakan.

Lama waktu hasil percobaan adalah dari attacker melakukan cracking password ke setiap user dan SSH-Server pada jaringan tersebut. Dan dari hasil pada tabel 1. menunjukkan semakin panjang karakter dan jenis password yang digunakan beragam maka waktu yang diperlukan semakin lama.

\section{KESIMPULAN DAN SARAN}

Penetrasi yang dilakukan dengan cara enumeration, untuk mendapatkan password dari user bisa dilakukan dengan cara mencari kemungkinan kecocokan dari password dan user menggunakan hydra selama 4 jam. Hal ini tergantung dari kompleksitas dari password dan resource yang digunakan attacker.

\section{DAFTAR PUSTAKA}

[1] R. Pangalila, A. Noertjahyana y J. Andjarwirawan, Penetration Testing Server Sistem Informasi Manajemen dan Website Universitas Kristen Petra, Jurnal Infra, Vols. $\% 1$ de \%2 Vol 3, No 2, 2015.

[2] Y. Yunanri , I. Riadi y A. Yudhana, «Analisis Keamanan Webserver Menggunakan Metode Penetrasi Testing ( PENTEST ), Annual Research Seminar (ARS), Vols. \%1 de \%2Vol 2, No 1, 2016.

[3] M. Dahlan, A. Latubessy y M. Nurkamid, Analisa Keamanan Web Server Terhadap Serangan Possibility Sql Injection Studi Kasus: Web Server UMK, Pros iding SNATIF, 2015.
[4] D. C. Angir, A. Noertjahyana y J. Andjarwirawan, Vulnerability Mapping pada Jaringan Komputer di Universitas X, Jurnal Infra, Vols. \%1 de \%2Vol 3, No 2, 2015.

[5] A. Amarudin, Desain Keamanan Jaringan Pada Mikrotik Router Os Menggunakan Metode Port Knocking, Jurnal TEKNOINFO, Vols. $\% 1$ de $\% 2$ Vol. 12 , No. 2, 2018. 